\title{
M-Learning Management Tool Development in Campus-Wide Environment
}

\author{
Anang Hudaya Muhamad Amin, Ahmad Kamil Mahmud, \\ Ahmad Izuddin Zainal Abidin, and Miziana Abdul Rahman \\ ICT/BIS Program, Universiti Teknologi PETRONAS, \\ Bandar Sri Iskandar, Perak Darul Ridzuan, Malaysia
}

\author{
ananghudaya@petronas.com.my kamilmh@petronas.com.my \\ izuddin z@petronas.com.my mizeeana@yahoo.com
}

\begin{abstract}
Mobile learning (M-Learning) integrates the current mobile and wireless computing technology with education primarily to enhance the effectiveness of the traditional learning process. One of the difficulties in implementing M-Learning is to deliver the content efficiently. This paper focuses on the development of M-Learning management tool in campus-wide environment using the Microsoft .NET infrastructure. User acceptance study was carried out to measure the feasibility of the M-learning management application development. The results of the study indicate a tendency towards the M-Learning acceptance in campus-wide environment. The main objective of the works that have been carried out is to develop a server-side M-Learning application using the Microsoft .NET infrastructure. The works that has been carried out act as preliminary work for future development of M-Learning application in campus-wide environment.
\end{abstract}

Keywords: M-Learning, E-Learning, Management Tool, Application Development, User Acceptance

\section{Introduction}

Education is the cornerstone of economic development in any nations (Ruttenbur, Spickler, \& Lurie, 2000). Traditionally, formal classroom-based education has been adopted, allowing a teacher and students to have face-to-face interactions (Moneta \& Moneta, 2002). However, this approach has noticeable drawbacks. Firstly, students’ physical presence and participation in group discussions in a learning centre are virtually required and form an integral part of the institution's curriculum (Bouras \& Philopoulos, 2001; Goodison, 2003). Secondly, the teacher has to adhere to the classroom schedules (Boyle, 1997; Jansen, Hooven, Jägers, \& Steenbakkers:, 2002). With the advancement of mobile technology, the traditional classroom-based learning has been supplemented by other forms of education capable of reaching out to a larger audience. Mobile

Material published as part of this publication, either on-line or in print, is copyrighted by the Informing Science Institute. Permission to make digital or paper copy of part or all of these works for personal or classroom use is granted without fee provided that the copies are not made or distributed for profit or commercial advantage AND that copies 1) bear this notice in full and 2) give the full citation on the first page. It is permissible to abstract these works so long as credit is given. To copy in all other cases or to republish or to post on a server or to redistribute to lists requires specific permission and payment of a fee. Contact Publisher@InformingScience.org to request redistribution permission. learning (M-Learning) offers possible solutions that address the shortcomings of the traditional classroom-based education. Since the use of mobile phones and handheld devices among students has dramatically increased, implementing M-Learning in academic institutions is of common interest (Keegan, 2002).

M-Learning is the teaching and learning processes through the use of mobile and 
handheld devices such as mobile phones, Personal Digital Assistants (PDAs), laptops, and tablet PCs. M-Learning is usually referred to as an extension of the existing e-learning applications. There is a suggestion that M-Learning enables learners the ability to receive learning on any device practically anywhere and anytime (Chabra \& Figueiredo, 2002). Hence, the mobility factor is the ultimate means of providing M-Learning services to the students or teachers. While the existing electronic learning (E-Learning) extends learning beyond physical classroom, M-Learning promises continued extension of learning process in a context-awareness manner. The key difference between E-Learning and M-Learning would be that M-Learning offers greater flexibility in where and when learning happens (Valentine, 2005). Moreover, M-Learning has the ability of providing rich mobile Internet experiences that are ubiquitous, accessible, rich in content, efficient, flexible, secure, reliable, and interactive (Wagner, 2005). The term E-Learning is analogous to online education. It is characterized by the separation of teachers and learners distinguishing it from face-to-face interaction, the influence of an educational organization differentiating it from self-study and private tutoring, the use of a computer network to present or distribute educational contents, and the provision of two-way communication via a computer network to enable students benefit from communication with each other, teachers, and staff (Geddes, 2005). Most of the ELearning applications exploit the availability of the World Wide Web (WWW) as a means of content delivery (IBM Mindspan Solution, 2002). One of the great advantages of the WWW is that it is platform-independent and able to support such media types as audio and video. From an educational perspective, teaching could now take place both synchronously and asynchronously (Keegan, 2002). With E-Learning, time and place are no longer restrictions as the learning experience can be tapped anywhere provided that one has a computer and access to the Internet (IBM Mindspan Solution, 2002; Jansen et al., 2002; Ruttenbur et al., 2000). It should be noted here that in E-Learning implementation, students would be able to receive services through the ELearning system, and at the same time would be able to communicate with others via the system.

With the existence of wireless and mobile communication technology, the initiative towards providing mobility in E-Learning has started (Heath et al., 2005). The M-Learning system, which

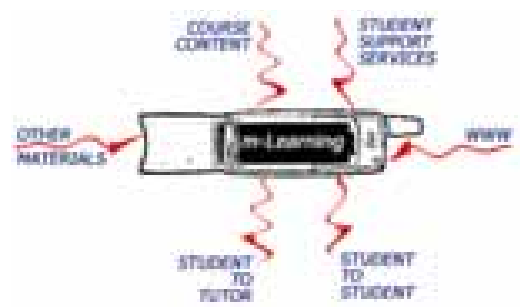

Figure 1: Mobile Learning Environment exploits the use of mobile and handheld devices, becomes a new approach in providing content delivery and assistance to the students (Heath et al., 2005; Holzinger, Nischelwitzer, \& Meisenberger, 2005). Figure 1 illustrates how MLearning works. By means of wireless Internet/intranet connection, students can receive course content located on a remote server, student support services and other materials that constitute the overall educational package.

In the development of any M-Learning applications, there are several challenges that should be observed. M-Learning should not convert the existing PC-based learning content into a mobile format, but to make a consideration on how the mobile devices can be used to strengthen the overall learning strategy (Ting, 2005). M-Learning should be able to provide complete independence of both location and time for users to use the application (Holzinger et al., 2005). Some of the challenges that should be taken into consideration in developing M-Learning application include the ability to provide adaptive learning environment, limited text display to support learning, and characteristics of instant communication in mobile network (Holzinger et al., 2005; Ting, 2005). 


\section{Related Works}

M-Learning is often defined as E-Learning through mobile devices (G Vavoula \& Karagiannidis, 2000). In this context, mobile device is considered as small, autonomous, and obtrusive enough to accompany people in every moment of their daily life, and that can be used for some form of learning (Griswold et al., 2004). These small tools can be seen as instruments for accessing contents, either stored locally on the device or reachable through interconnection. They can also be a tool for interacting with people, via voice and through the exchange of written messages, still and moving images.

There are many properties differentiating mobile devices from desktop computers. The former have impact on what is reasonable, useful, and even pleasant to do on such devices (Bae, Lim, \& Lee, 2005; Holzinger et al., 2005). For example, the output (screen size and resolution capabilities), input (keypad, touch-screen), processing power and memory size, and supported applications.

The concept of mobility - the anytime, anywhere capabilities of mobile devices encourage learning experiences outside classroom-based environment. Inside the classroom, mobile devices provide students with the capabilities to link to activities that do not correspond with either the teacher's agenda or the curriculum (Sharples, 2003). Apart from that, lifelong learners would also need effective tools to record, organise, and reflect on their mobile learning experiences (Vavoula, 2004; Vavoula \& Karagiannidis, 2000). The concept of mobility is related to how the design of the M-Learning application should be adopted. M-Learning should be simple to use and has value-added functionality. It should be possible to use M-Learning system without reading a user manual and the experience of studying with the help of such devices should be interesting and engaging (Trifonova \& Ronchetti, 2003). An initiative that has been carried out by (Bae et al., 2005) include the modeling and development of M-Learning application using the existing WAP and HTML infrastructure. The works that have been carried out in this paper will be focusing on the development of server-side M-Learning application that will support the mobility factor, which include the content delivery method.

Another issue that has been identified by the authors, with regards to the M-Learning concept is the flexibility of the M-Learning application. M-Learning application should be developed in the sense that it would be able to be supported by different devices, such as smart phones, PDAs, and laptops. There are several initiatives that have been carried out by other researchers in developing M-Learning applications. Project Numina (Heath et al., 2005) is one of the examples of such development. In this project the full-course content and management system was developed using the existing Mobile Learning Engine (MLE). MLE is a Java-based Mobile Learning Development Tool. Similarly, the initiative carried out by (Holzinger et al., 2005) in developing M-Learning application for Healthcare domain using Mobile Interactive Learning Objects (MILOs). These initiatives show that the development of M-Learning application has been established by other researchers. The main difference that has been carried out by the authors as compared to these related works is such that the development of M-Learning Management Tool is developed using .NET environment introduced by Microsoft. The main reason behind this adoption of .NET environment is such that the architecture would be able to provide flexibility to the user to use the system. With the contents being delivered using ASP.NET format, it would be readable by not only mobile devices, but other existing desktop-based web browsers. The development of this MLearning management tool also revealed that the development of server-side M-Learning application is possible. Furthermore, this work heavily focuses on the management tool, rather than the contents delivery. Figure 2 shows the architecture of this M-Learning Management Tool. 


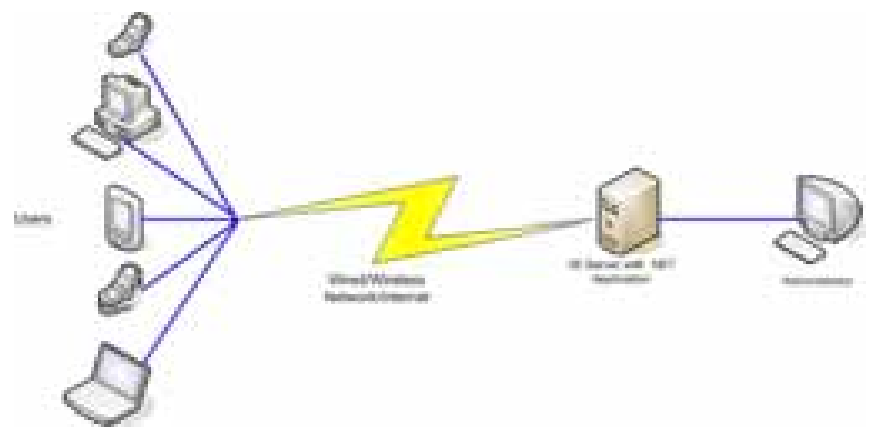

Figure 2: M-Learning Management Tool Architecture
Another challenging issue in $\mathrm{M}$ Learning is the device ownership (Wagner, 2005). Both personal and group learning are most effectively supported when each student has access to a device. The ownership of the device is thus a key consideration. Both tangible and intangible benefits can accrue through the use of mobile devices. Intangible benefits include the sense of belonging with the device and personal commitment and

comfort. Ownership is stated as a prerequisite for engagement allowing students to have the potential to go beyond the necessary and play with it to explore its potential. Personal ownership does, however, present a challenge to the institutional control of the technology (Savill-Smith \& Kent, 2003).

This paper focuses on the development of M-Learning management tool in campus-wide environment. The tool has been developed for the use of students in the campus. The management tool enables students to view the contents for courses they enroll in, the timetables, assessment reports, and assignments anywhere, and anytime on campus. The main issues to be discussed include the mobility factor, as well as the flexibility of M-Learning application. These issues have been explored, with regards to the development of server-side M-Learning management tool using the .NET architecture. The works that has been carried out act as a preliminary work for future development of M-Learning application in campus-wide environment. The paper consists of several sections namely, Related Works, M-Learning Management Tool Development, Results and Discussion, and Conclusion.

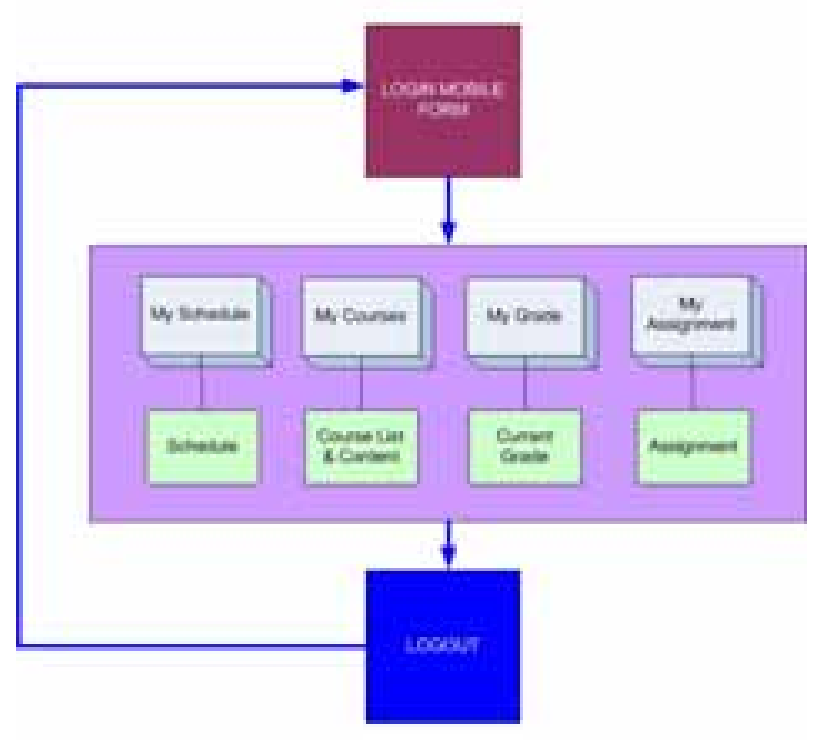

Figure 3: Conceptual Flow Model of M-Learning Management Tool

\section{M-Learning Management Tool Development}

In developing M-Learning tool for this study, the normal system development methodology has been adopted, which include four main phases: planning, analysis, design, and implementation. Figure 3 shows the conceptual flow model that has been developed for this M-Learning management tool. It should be noted that there are four core modules that have been included: My Courses, My Schedule, My Grade, and My Assignment. Each of these modules has been built on mobile web form, which is different from the normal web forms. Each mobile web form can have multiple forms, while normal web form can have a single form per page. In developing this ap- 
plication, the authors have adopted Microsoft .NET architecture and uses Microsoft Visual Studio as the development tool. In achieving the mobility factor, the authors have adopted the Microsoft Mobile Internet Toolkit (MMIT) as the means to develop this M-Learning application. The authors also found out that MMIT can generate different mark-up language for different devices. This actually simplifies the development process in the sense that application would only need to be written once and the different languages would be generated by the .NET framework. The toolkit has been tested with multiple devices including Nokia 6210, Pocket PC with Microsoft Internet Explorer v.4.5., and Sony Ericsson R380.

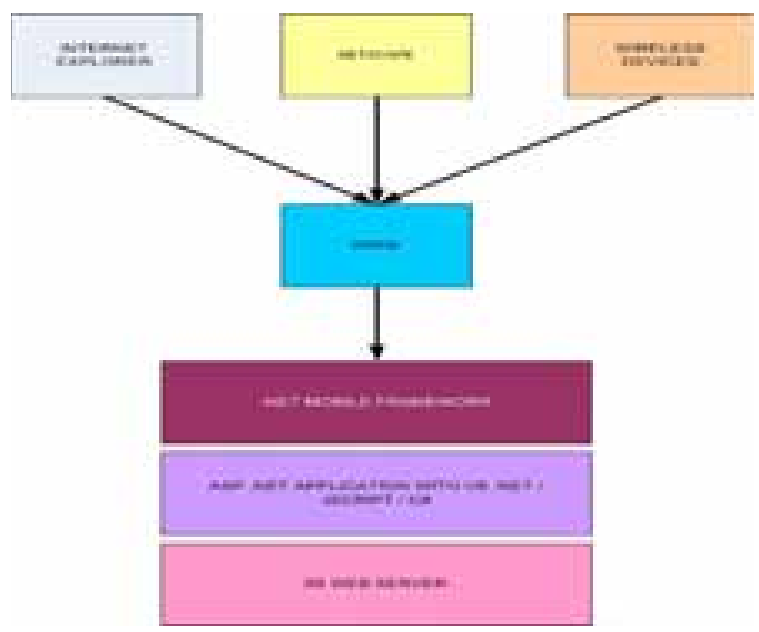

Figure 4: Microsoft Mobile Internet Architecture

MMIT is built on Microsoft ASP .NET Web Forms. Since the toolkit is an extension of ASP .NET, it supports languages like VB.NET, C\#, and JScript.NET. The toolkit is also integrated with Microsoft Visual Studio .NET. Figure 4 shows the MMIT Framework in mobile computing applications. The advantage of implementing this M-Learning Management Tool over MMIT is such that it will be able to support other means of access. For example, the user would not only be able to access the tool by using mobile devices. This system would only able to be accessed via desktop-based web browsers (Internet Explorer, Netscape).

Throughout the development of the MLearning management tool, the authors discovered that although M-Learning is a revolution of E-Learning, to effectively build and deliver, it requires rethinking, reinvestigating, and re-evaluating the human-computer interaction in the mobile environment. The existing ELearning frameworks may not work very well with M-Learning: the interaction experience in MLearning is different from other types of learning.
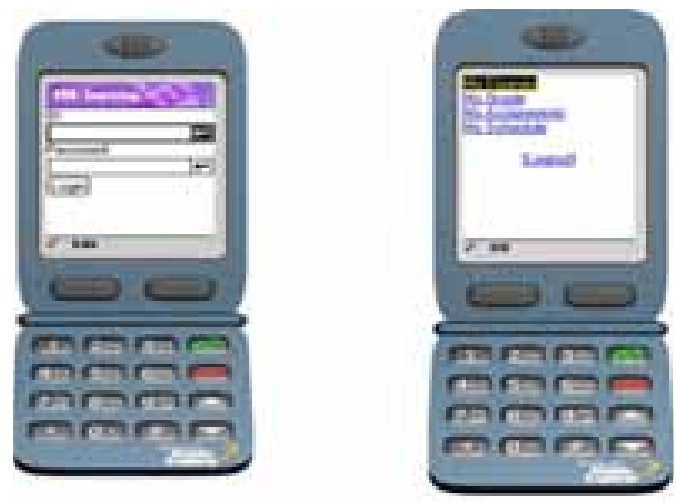

Figure 5 shows the login page and the default page of the system. Once user has been logged in, they will be directed to the main page of the system.

\section{Figure 5: Login Page and Default Page of M-Learning}



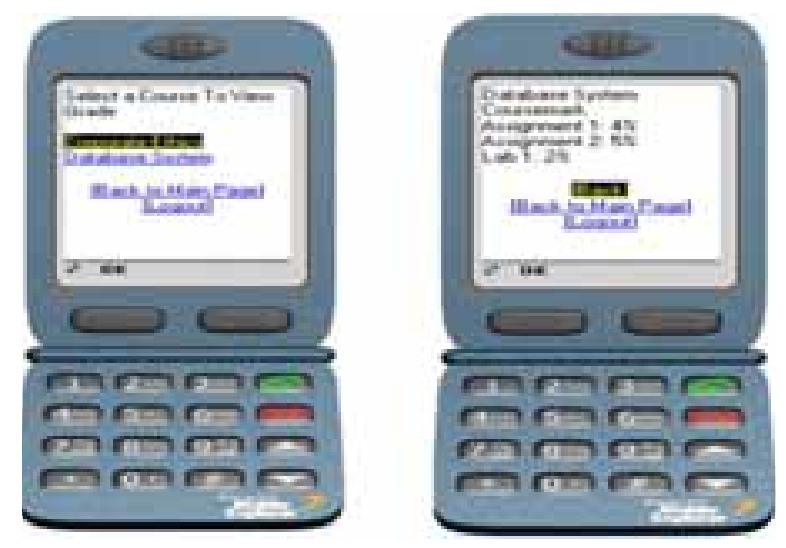

Figure 6: Course Grade Module
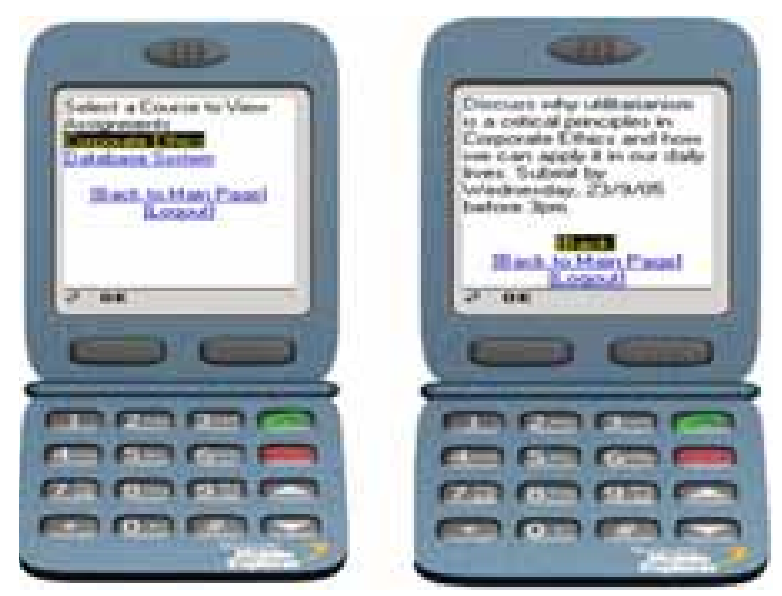

Figure 7: Course Assignment Module
The main page consists of four modules that have been previously explained. It should be noted that the development has been done using the emulator provided by the MMIT. Figure 6 shows the page for the grades module. This module shows the marks for labs, projects and tests. This module allows the students to be informed of their performance in the course.

The assignment module shown in Figure 7 enables students to open text file from lecturers to view the assignments that has been given.

\section{Results \& Discussion}

Generally, the authors' research was also aimed at the understanding interaction experience in $\mathrm{M}$ Learning by examining a broad range of aspects of M-Learners and their environment. In achieving this, acceptance study has been adopted. The user acceptance study for M-Learners has been sub-categorized into two main areas including interaction experience in the mobile environment as well as the usability of M-Learning management tool. To understand the interaction experience in the mobile environment, three important characteristics were examined: understanding of the mobile learners (including their characteristics, psychological, and physical capability), understanding of the M-Learning environment (the motivations and circumstances surrounding mobile device usage and adoption), and understanding of mobile experience which differs from desktop computing. This study has adopted a survey method by the means of questionnaire to obtain the feedbacks from the users, on the M-Learning tool that has been developed, as well as to obtain the data that reflects towards the study on the acceptance of users for M-Learning method.

The purpose of the questionnaire is to elicit information on the effectiveness of M-Learning as a learning management tool. It is an excellent way of obtaining either quantitative or qualitative data, since the user responses are written and can be tallied to illustrate user preferences. Ques- 
tionnaires can only evaluate users' opinions about the user interface, not their behavior while using the M-Learning management tool.

For these reasons, the authors decided to adopt a variant of the Delphi survey approach. In the early 1950s, the term Delphi was used to describe a reliable consensus of opinion, obtained from group of experts by a series of intensive questionnaires interspersed with controlled opinion feedback (Linstone \& Turoff, 1975). This approach is characterized as 'a method for the systematic solicitation and collation of judgments on a particular topic through a set of carefully designed sequential questionnaires interspersed with summarized information on feedback of opinions derived from earlier responses' (Delbecq, 1975). Delphi is particularly useful when accurate information is unavailable or expensive to obtain, or where evaluation models require subjective inputs to the point where they become the dominating parameters (Linstone \& Turoff, 1975). The survey is the most common technique of Delphi application.

For the purpose of this study, we selected 30 students as the evaluators for the M-Learning tool, and they also involved in the survey that has been conducted.

At first, responses to the idea of M-Learning were mixed, as many were immediately accepting, while some were immediately rejecting. Irrespective of their initial views, most responded with questions about the nature, format and purpose of M-Learning. Respondents were quite difficult to adapt to the term M-Learning due to its new concept in education. The initial tendency was for the respondents to consider the benefits and drawbacks of M-Learning for themselves as individuals. Those initially most favorable towards the idea argued that they would benefit from it. However, the ones who disagreed towards the idea argued that they would benefit more from the traditional learning system.

Generally, students were interested in the technology that M-Learning could offer them. Another plus factor was that most of them owned at least one mobile device, the most common being mobile phones. Figure 8 shows that 11 percent strongly agreed and 38 percent agreed while 25 percent strongly disagreed. Another 18 percent disagreed while the remaining was uncertain. These obtained data show that the acceptance level of respondents is still cannot be considered high. This may due to the inexperience use of mobile devices for course management, as well as the lack of proper documentation on how the system should be used.

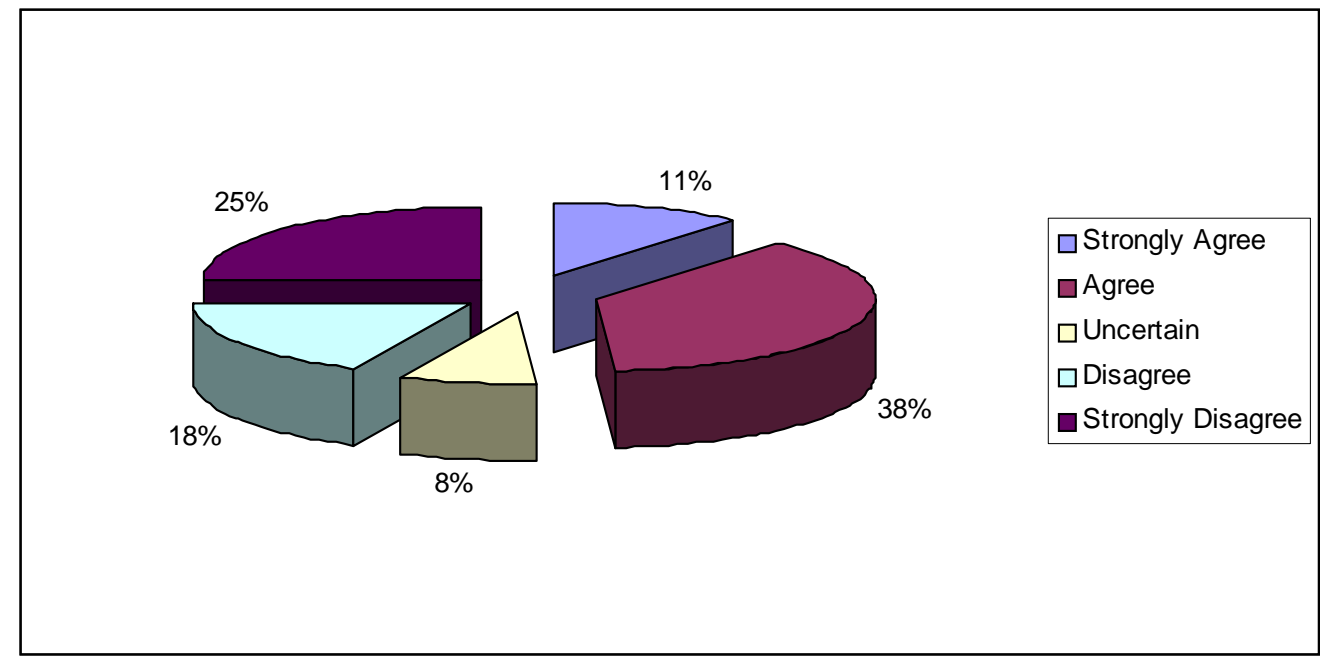

Figure 8: Responses on User Acceptance 


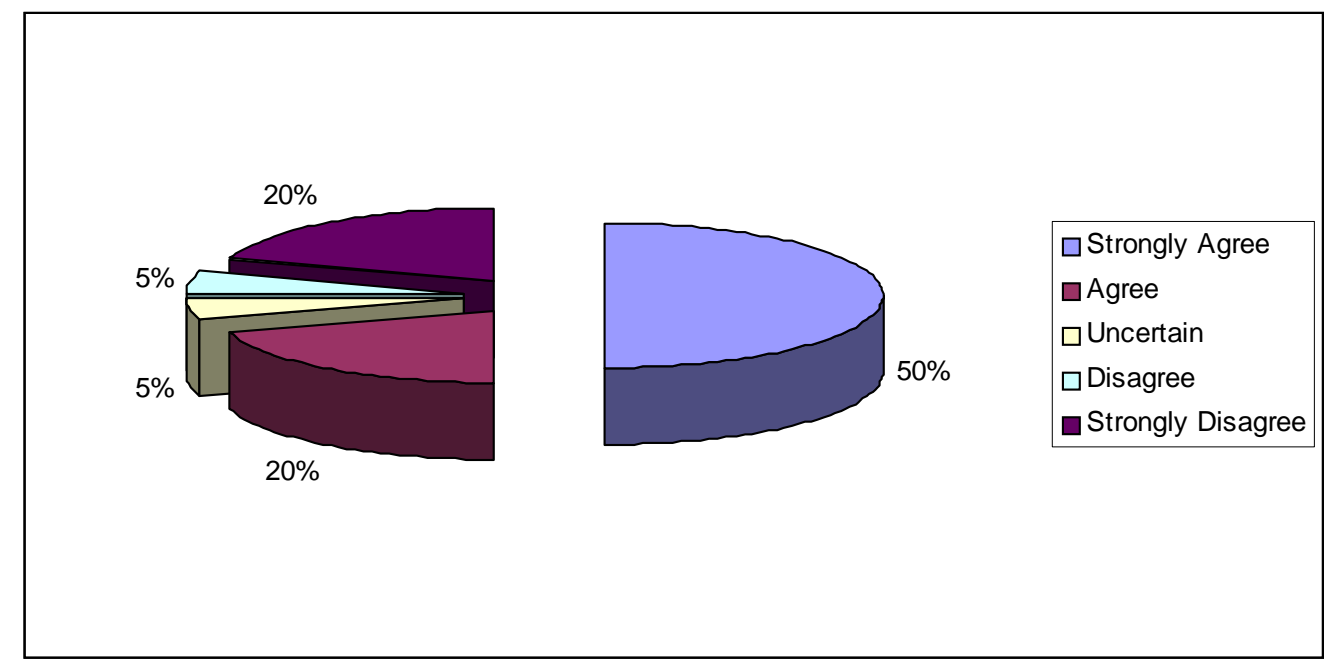

Figure 9: Responses on User-Friendliness

Based on Figure 9, the authors found that 50 percent strongly agreed that the system was user friendly and easy to use. Another 20 percent agreed, while 5 percent were uncertain about the management tool's user friendliness. Both 5 percent and 20 percent disagreed and strongly disagreed on the user friendliness of the system. The result shows that the M-Learning management tool developed has a good navigation and users would be able to use it without any difficulties.

Figure 10 shows an imbalanced distribution between those who agreed and those who did not. About 62 percent strongly agreed that M-Learning could improve educational efficiency while 9 percent strongly disagreed and still preferred the current learning styles. The rest showed that 18 percent agreed, 9 percent disagreed while another 2 percent are uncertain. The result obtained revealed that the respondents believed that there is a tendency on which the M-Learning would be able to improve the educational efficiency, with regards to the usage of M-Learning management tool.

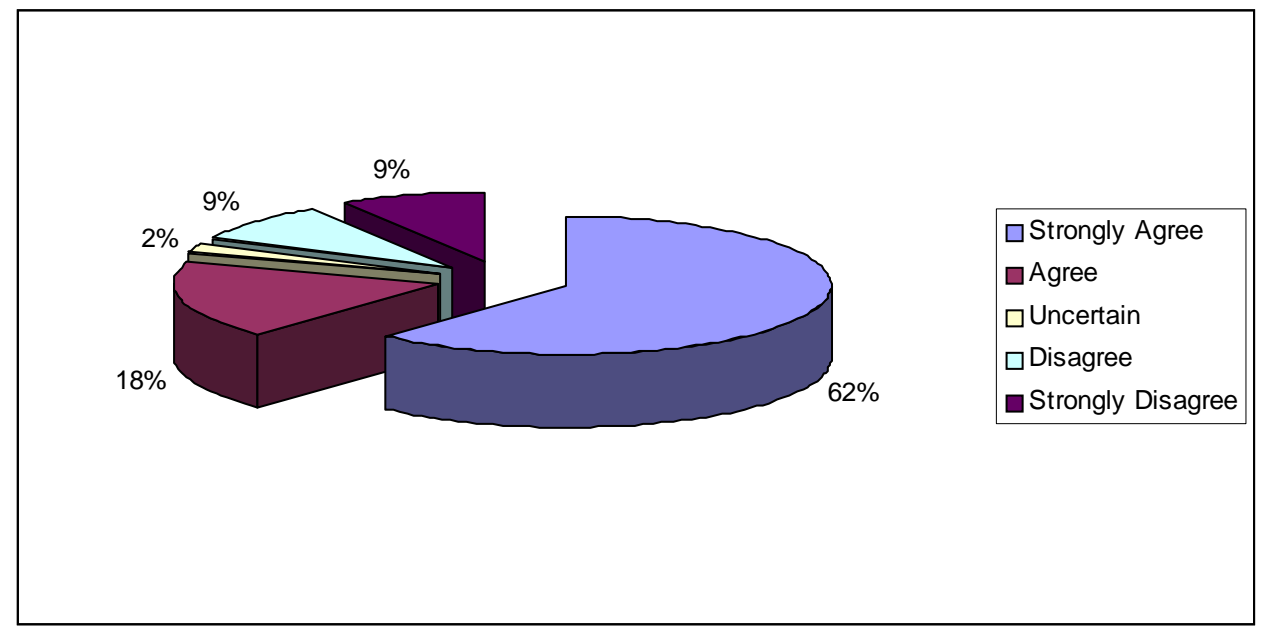

Figure 10: Responses on Didactic Efficiency 
Figure 11 shows that 33 percent disagreed on the feasibility of the system, with most of them disagreed that it was not necessary to use graphics and illustrations in order for M-Learning to be effective, considering the screen limitation factor. About 20 percent strongly disagreed while 8 percent remained uncertain. Both 22 percent and 17 percent strongly agreed and agreed on technical feasibility. This shows the mixed reactions of users with regards to the use of visual elements in M-Learning management tool.

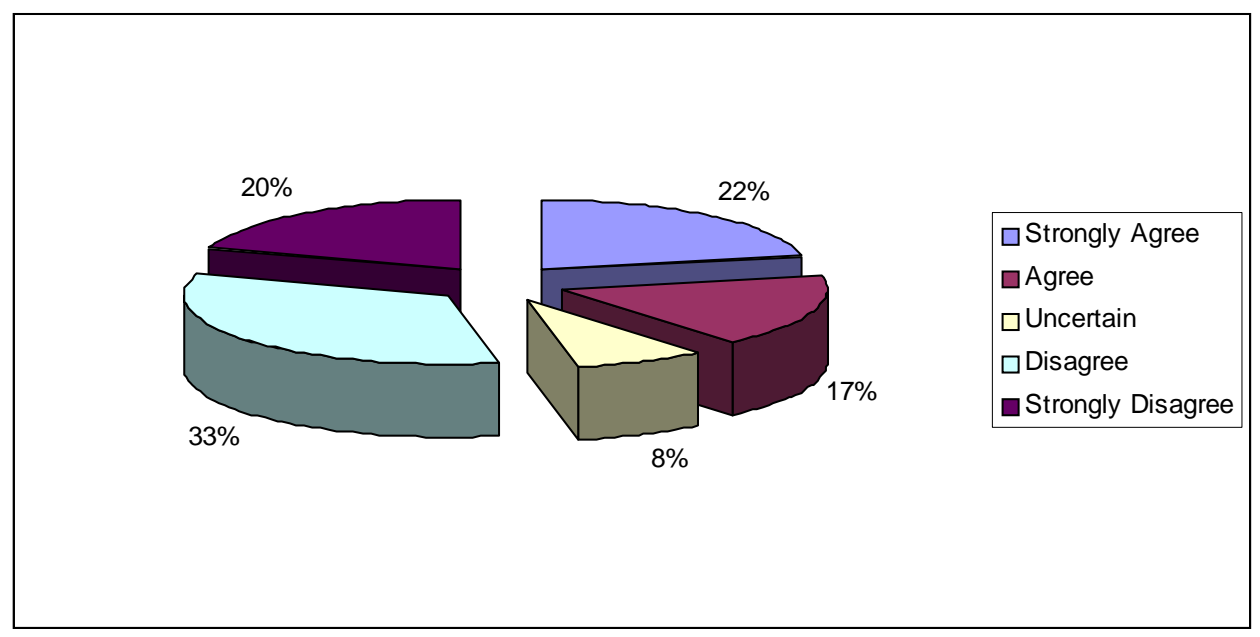

Figure 11: Responses on Feasibility of the System

\section{Conclusion}

The development of M-Learning management tool has been completed. From the development process, as well as the results of the development, the issues on mobility and flexibility of MLearning application has been identified. The development of server-side M-Learning management tool using .NET architecture has shown that the mobility and flexibility issues could be resolved. The .NET architecture has the capability to provide easy access from mobile devices to the application server, as well as the flexibility, in terms of different devices used as the front-end of the system. This M-Learning management tool provides users with a new look on learning style, where they can access information they want using a mobile device, anywhere and anytime.

The authors also discovered that understanding interaction experience is not an entirely new area in human computer interaction (HCI), but there is no agreed framework that can actually guide designers and developers towards the development of usable M-Learning systems. There is considerable work to be accomplished on many fronts - HCI, mobile technology, learning communities, and content development before the potential of M-Learning comes to fruition. In addition, the implementation of M-Learning Management tool using .NET architecture has been able to provide greater flexibility for the users to use the system, regardless whether the mobility is required or not.

After analyzing the survey data, the authors found out that the concept of M-Learning might be of an interest to the users specifically in a campus-wide environment, provided that it can assist them in their learning process. Apart from that, it seems that M-Learning can be more easily acceptable if it is able to provide at least the same learning experience based on the current educational style, and able to provide an interactive learning environment for the users. Those who disagree prefer to stick to the current learning style or might be resistant to technology changes. Us- 
ers are very concerned with the usability of the system as this will be the determining factor in feasibility of the system.

\section{References}

Bae, Y. K., Lim, J. K., \& Lee, T. W. (2005, July 5-8). Mobile learning system using the ARCS strategies. Proceedings of the 5th International Conference on Advanced Learning Technologies, Taiwan.

Bouras, C., \& Philopoulos, A. (2001). e-Learning through distributed virtual environments. Journal of Network and Computer Applications, 24. Available online at http://citeseer.nj.nec.com/456858.html

Boyle, T. (1997). Design for multimedia learning. London: Prentice Hall.

Chabra, T., \& Figueiredo, J. (2002). How to design and deploy handheld learning. Retrieved December 8, 2002 from http://www.empoweringtechnologies.net/eLearning/eLearning_expov5_files/frame.htm

Delbecq, A. L. (1975). Group techniques for program planning: A guide to nominal group and Delphi processes. Scott, Foresman \& Co.

Geddes, S. J. (2005). Mobile learning in the 21st century: Benefit for learners. The Knowledge Tree, 6. Available at http://knowledgetree.flexiblelearning.net.au/edition06/download/geddes.pdf

Goodison, T. (2003). Integrating ICT in the classroom: A case study of two contrasting lessons. British Journal of Educational Technology, 34(5), 549-566.

Griswold, W. G., Shanahan, P., Brown, S. W., Boyer, R., Ratto, M., Shapiro, R. B., Truong, T. M. (2004). ActiveCampus: Experiments in community-oriented ubiquitous computing. Computer, 37(10), 73-81.

Heath, B. P., Herman, R. L., Lugo, G. G., Reeves, J. H., Vetter, R. J., \& Ward, R. W. (2005). Project Numina: Enhancing student learning with handheld computers. IEEE Computer Society, 38(6), 46-53.

Holzinger, A., Nischelwitzer, A., \& Meisenberger, M. (2005, March 8-12, 2005). Mobile phones as a challenge for M-Learning: Examples for mobile interactive learning objects (MILOs). Proceedings of the 3rd International Conference on Pervasive Computing and Communications Workshop 2005, Hawaii, USA.

IBM Mindspan Solution. (2002). E-Learning: Implementing the 4-tier blended learning model. Retrieved from http://www.ibm.com/Mindspan

Jansen, W., Hooven, H. M. V. D., Jägers, H. P. M., \& Steenbakkers, G. C. A. (2002). The added value of elearning. Proceedings of the Informing Science and IT Education Conference: InSITE 2002, June 1921, 2002, Cork, Ireland. Retrieved from http://proceedings.informingscience.org/IS2002Proceedings/papers/Janse124Added.pdf

Keegan, D. (2002). The future of learning: From E-Learning to M-Learning. Retrieved September 7, 2005 from http://learning.ericsson.net/leonardo/thebook/chapter4.html\#milearn

Linstone, H. A., \& Turoff, M. (1975). The Delphi method: Techniques and applications. Addison-Wesley.

Moneta, S. K., \& Moneta, G. B. (2002). E-Learning in Hong Kong: Comparing learning outcomes in online multimedia and lecture versions of an introductory computing course. British Journal of Educational Technology, 33(4), 423-433.

Ruttenbur, B. W., Spickler, G. C., \& Lurie, S. (2000). E-Learning: The engine of the knowledge economy. Memphis: Morgan Keegan.

Savill-Smith, C., \& Kent, P. (2003). The use of palmtop computers for learning. Learning and Skills Development Agency. Retrieved May 20, 2005, from http://www.m-learning.org/docs/the_use_of_palmtop_computers_for_learning_sept03.pdf

Sharples, M. (2003). Disruptive devices: Mobile technology for conversational learning,. International Journal of Continuing Engineering Education and Lifelong Learning, 12(5/6), 504-520. 
Ting, R. Y. (2005). Mobile learning: Current trend and future challenges. Proceedings of the Fifth IEEE International Conference on Advanced Learning Technologies 2005.

Trifonova, A., \& Ronchetti, M. (2003). A general architecture for M-Learning. Paper presented at the $M$ ICTE 2003 Conference, USA.

Valentine, E. (2005). Unplugged learning: A report on the rise of mobile technology in learning. 14th National VET Research Conference, Albury - Wodonga, July, 2005. Retrieved from http://cms.steo.govt.nz/NR/rdonlyres/6C03CDFA-70E7-4179-90E57637BA267D7C/0/UnpluggedLearningFinalNovember04.doc

Vavoula, G. (2004). KLeOS: A knowledge and learning organization system in support of lifelong learning. Unpublished PhD, University of Birmingham.

Vavoula, G., \& Karagiannidis, C. (2000). Designing mobile learning experiences. Institute of Educational Technology.

Wagner, K. (2005). Enabling mobile learning, Educause Review. May/June.

\section{Biographies}

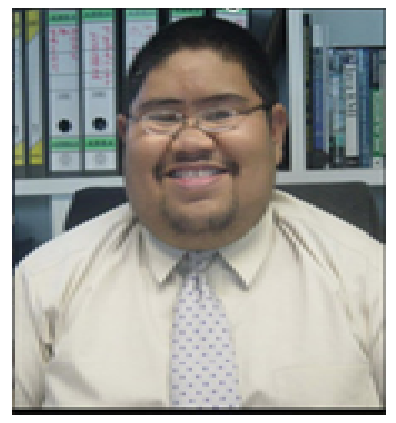

Anang Hudaya Muhamad Amin is currently working as lecturer and researcher at Universiti Teknologi PETRONAS, Malaysia. His research interests include mobile applications development, agent-based computing and Quality of Service (QoS) in network environment. Received his Master of Network Computing from Monash University, Australia and BTech(Hons.) in Information Technology from Universiti Teknologi PETRONAS, Malaysia.

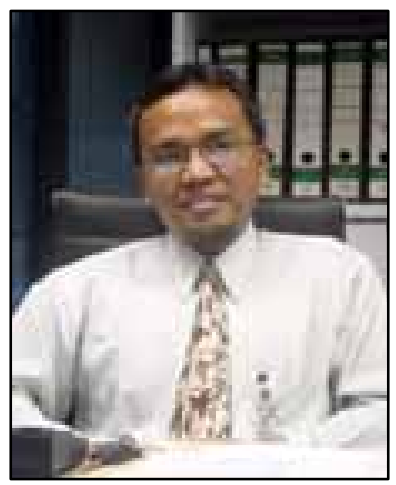

A Kamil Mahmood is a Senior Lecturer at Universiti Teknologi PETRONAS. He earned his PhD from the University of Salford, UK while his M Sc and B Sc from the University of Iowa, USA. He was a system analyst, associate lecturer to Manchester Metropolitan University, UK and external examiner to a number of academic institutions in Malaysia. His research has focused on the socio-technical issues including e-commerce and the use of embodied agents. Currently, he is heading ICT/BIS program and supervising 4 post graduate students. 


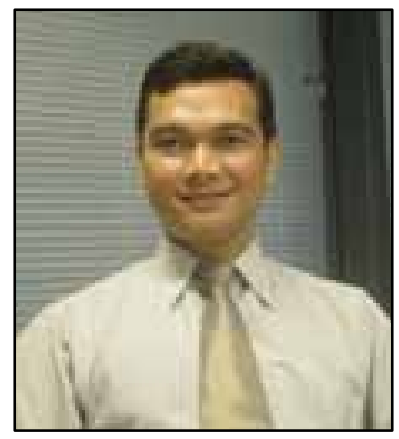

Ahmad Izuddin Zainal Abidin is currently working as a lecturer and a researcher at Universiti Teknologi PETRONAS, Malaysia. His research interests include mobile applications development, e-business, and algorithms. He graduated with MS Computer Science and BS Computer Science from State University of New York and University of Pittsburgh, respectively.

Miziana Abdul Rahman is currently pursuing undergraduate studies at Universiti Teknologi PETRONAS, Malaysia. Her research interests include human-computer interaction (HCI) and mobile applications development. 